\title{
Parasitism and host dispersal plasticity in an aquatic model system
}

2 Running title: Parasitism and dispersal plasticity

4 Authors details:

5 Giacomo Zilio ${ }^{1^{*}}$, gcm.zilio@gmail.com, ORCID ID: https://orcid.org/0000-0002-4448-3118

6 Louise S. Nørgaard ${ }^{1,2}$, Inorga10@ hotmail.com, ORCID ID: https://orcid.org/0000-0002-0938-0017

7 Giovanni Petrucci ${ }^{1}$, giovannipetrucci82@gmail.com, ORCID ID: unavailable

8 Nathalie Zeballos ${ }^{1,3}$, nathalie.zeballos@cefe.cnrs.fr, ORCID ID: unavailable

9 Claire Gougat-Barbera ${ }^{1}$, claire.gougat-barbera@umontpellier.fr, ORCID ID: unavailable

10 Emanuel A. Fronhofer ${ }^{1}$, emanuel.fronhofer@umontpellier.fr, ORCID ID: https://orcid.org/0000-0002-2219-

$11784 \mathrm{X}$

12 Oliver Kaltz ${ }^{1 *}$, oliver.kaltz@umontpellier.fr, ORCID ID: https://orcid.org/0000-0002-7154-0456

${ }^{1}$ ISEM, University of Montpellier, CNRS, EPHE, IRD, Montpellier, France.

${ }^{2}$ School of Biological Sciences, Monash University, Melbourne 3800, Australia.

${ }^{3}$ CEFE, University of Montpellier, CNRS, EPHE, IRD, Montpellier, France.

*Corresponding authors: gcm.zilio@gmail.com, oliver.kaltz@umontpellier.fr

\section{Acknowledgements section}

This work was supported by the Swiss National Science Foundation (grant no. P2NEP3_184489) to GZ, and by the 2019 Godfrey Hewitt mobility award granted to LN by ESEB, and by the. This is publication ISEM-

XXXX-XXX of the Institut des Sciences de l'Evolution.

\section{Author Contributions section}

OK, GZ, LN, NZ and EAF conceived the study. OK, GZ, LN and NZ designed the experiments. GZ, LN, NZ, CGB and OK performed the experimental work. GZ, EAF, OK, GP and NZ performed the statistical analysis. All authors interpreted the results and contributed to the writing of the manuscript.

\section{Conflict of Interest statement}

The authors have no conflict of interest to declare. 


\section{Abstract}

Dispersal is a central determinant of spatial dynamics in communities and ecosystems, and various ecological factors can shape the evolution of constitutive and plastic dispersal behaviours. One important driver of dispersal plasticity is the biotic environment. Parasites, for example, influence the internal condition of infected hosts and define external patch quality. Thus state-dependent dispersal may be determined by infection status and context-dependent dispersal by the abundance of infected hosts in the population. A prerequisite for such dispersal plasticity to evolve is a genetic basis on which natural selection can act. Using interconnected microcosms, we investigated dispersal in experimental populations of the freshwater protist Paramecium caudatum in response to the bacterial parasite Holospora undulata. For a collection of 20 natural host strains, we found substantial variation in constitutive dispersal, and to a lesser degree in dispersal plasticity. First, infection tended to increase or decrease dispersal relative to uninfected controls, depending on strain identity, potentially indicative of state-dependent dispersal plasticity. Infection additionally decreased host swimming speed compared to the uninfected counterparts. Second, for certain strains, there was a weak negative association between dispersal and infection prevalence, such that uninfected hosts tended to disperse less when infection was more frequent in the population, indicating context-dependent dispersal plasticity. Future experiments may test whether the observed differences in dispersal plasticity are sufficiently strong to react to natural selection. The evolution of dispersal plasticity as a strategy to mitigate parasite effects spatially may have important implications for epidemiological dynamics.

\section{Keywords:}

50 Condition-dependent dispersal, dispersal plasticity, eco-evolution, epidemiology, Holospora undulata, hostparasite interactions, Paramecium caudatum, reaction norms, spatial dynamics 


\section{Introduction}

Dispersal, broadly defined as the movement of individuals with consequences for gene flow, is a key lifehistory trait (Bonte \& Dahirel, 2017) driving metapopulation and metacommunity dynamics as well as the geographic distribution of species (Hanski, 1999). In recent years, the study of dispersal and dispersal syndromes have received increasing interest (Clobert et al., 2012; Stevens et al., 2014), as landscapes are seeing large-scale environmental alterations and fragmentation, rendering dispersal crucial to potentially mitigate these changes (Parmesan \& Yohe, 2003; Cote et al., 2017). Although dispersal is often considered a constitutive trait, plastic dispersal behaviour represents a flexible alternative, responding to changes in the internal condition of an individual (state-dependent dispersal) and to external environmental factors (context-dependent dispersal) (Clobert et al., 2009). State-dependent dispersal has been associated with variation in factors such as body size, the developmental stage or sex of individuals (Bowler \& Benton, 2005). In contrast, context-dependent dispersal decisions may be based on cues that provide information on biotic and abiotic patch properties, such as food availability, population density, or kin competition (see Ronce, 2007 and references therein).

In communities, dispersal plasticity may be advantageous in mitigating adverse interactions with other species (Fronhofer et al., 2015a). Parasites are particularly interesting in this respect: they are ubiquitous and impose strong selection pressures, and potentially drive the evolution of both state-dependent and contextdependent dispersal of their hosts (Iritani \& Iwasa, 2014; Iritani, 2015; Narayanan et al., 2020; Deshpande et al., 2021). Empirical studies have investigated aspects of parasite-related dispersal (see below), but still little is known about the genetic basis of this kind of dispersal plasticity and its adaptive significance.

State-dependent dispersal may relate to morphological or physiological changes induced by parasites. The exploitation of host resources might decrease general activity levels, and thereby reduce movement and dispersal. Such negative effects have been documented for various organisms (Binning et al., 2017; Nørgaard et al., 2019; Baines et al., 2020), even though it is not necessarily a general rule (Nelson et al., 2015; Csata et al., 2017). While in many examples the observed effects may represent side effects, theory has identified conditions under which increased (but also decreased) dispersal when infected is adaptive, namely under kin selection (Iritani \& Iwasa, 2014; Iritani, 2015) or when infection can be lost during dispersal (Shaw \& Binning, 2016; Daversa et al., 2017). Indeed, increased dispersal of infected hosts is not uncommon (Suhonen et al., 2010; Brown et al., 2016), although it may also be the result of parasite manipulation (Lion et al., 2006; Martini et al., 2015). 
bioRxiv preprint doi: https:/doi.org/10.1101/2020.07 30.228742; this version posted March 7, 2021. The copyright holder for this preprint (which was not certified by peer review) is the author/funder, who has granted bioRxiv a license to display the preprint in perpetuity. It is made available under aCC-BY-NC 4.0 International license.

(Weisser et al., 1999; de la Pena et al., 2011). A recent multi-species study further showed that chemical predator-related cues increase dispersal probability (Fronhofer et al., 2018). Such cues may also exist in hostparasite systems, where infection-avoidance behaviour is well known (Behringer et al., 2006; Curtis, 2014). Recent theory shows that hosts may indeed evolve reaction norms, with dispersal being a function of the parasite infection prevalence (Deshpande et al., 2021). To date, few if any empirical studies have tested for the existence of such plastic population-level responses (French \& Travis, 2001).

Adaptive phenotypic plasticity is a powerful solution in many situations (Chevin et al., 2013; Stamp \& Hadfield, 2020), and just like constitutive traits, it has a genetic basis on which selection can act (Pigliucci, 2005; Garland \& Kelly, 2006; Laitinen \& Nikoloski, 2019). Dispersal-related traits have such a genetic basis (Saastamoinen et al., 2018) and constitutive dispersal can evolve rapidly in a parasite context (Koskella et al., 2011; Zilio et al., 2020). However, the genetics and evolution of dispersal plasticity is less well studied. In fact, how plastic dispersal varies between different genotypes under parasite challenge is rarely evaluated in empirical studies (Suhonen et al., 2010; Fellous et al., 2011), or the genetic diversity is treated as a random effect (Csata et al., 2017). Moreover, the number of genotypes evaluated is usually small, making it difficult to draw general conclusions (Leggett et al., 2013).

Here, using interconnected microcosms, we tested a collection of 20 natural strains of Paramecium caudatum for dispersal in the presence and absence of the bacterial parasite Holospora undulata. Previous work in this system had shown that infection reduces dispersal for a small number of strains (Fellous et al., 2011; Nørgaard et al., 2021). The first objective of the present study was to test whether this negative effect was general, or whether strains varied in infection-state dependent dispersal. Second, we tested for genetic variation in context-dependent dispersal by comparing the dispersal of uninfected hosts over a range of infection prevalences that had naturally established in the experimental populations. We found that parasite reduced or increased dispersal levels depending on strain identity, indicating a state-dependent plastic response of the infected hosts, but no general negative effect of infection. Furthermore, increasing infection prevalence tended to reduce host dispersal for certain strains, suggesting context-dependent dispersal plasticity of uninfected hosts. Such genetic variation in dispersal plasticity may provide the raw material for parasite-mediated selection, in natural settings or for the purpose of experimental evolution.

\section{Materials and methods}

\section{Study system}

Paramecium caudatum is a freshwater filter-feeding protist from stagnant waters of the Northern hemisphere (Wichterman, 2012). Like all ciliates, paramecia have a macronucleus for somatic gene expression and a germ-line micronucleus, used for sexual reproduction. The micronucleus can be infected by 
bioRxiv preprint doi: https://doi.org/10.1101/2020 07.30.228742; this version posted March 7, 2021. The copyright holder for this preprint (which was not certified by peer review) is the author/funder, who has granted bioRxiv a license to display the preprint in perpetuity. It is made available under aCC-BY-NC 4.0 International license.

Holospora undulata, a gram-negative alpha-proteobacterium (Fokin, 2004). Infectious spores are released for horizontal transmission after host cell division or upon host death. Infectious spores are immobile and therefore rely on host movement or water current for their own dispersal. Vertical transmission occurs when hosts divide mitotically. Infection reduces $P$. caudatum division and survival (Restif \& Kaltz, 2006) and also host dispersal (Fellous et al., 2011; Nørgaard et al., 2021).

\section{Experimental setup}

Preparation of replicates. We established mass cultures for a collection of 20 genetically distinct strains of $P$. caudatum from different geographical regions (provided by S. Krenek, TU Dresden, Germany; Table S1, Supplementary Information). Distributed over two experimental blocks, 6 infected replicate cultures were established for each strain (20 strains $\times 2$ blocks $\times 3$ replicates $=120$ replicates). Inocula were prepared from a mix of infected stock cultures in the lab, all originating from a single isolate of $H$. undulata established in 2001 (Dohra et al., 2013). Following standard protocols for the extraction of infectious spores (e.g., Nørgaard et al., 2021) we used c. $10^{4}$ spores to inoculate samples of c. $3-5 \times 10^{3}$ host cells in $1.5 \mathrm{~mL}$ per assay replicate. Four days after inoculation, when infections have established, we expanded the cultures by regular addition of lettuce medium (supplemented with the food bacterium Serratia marcescens), until a volume of $50 \mathrm{~mL}$ was reached. In the same way, we set up three uninfected control populations per strain, giving a total of 180 experimental cultures. After three weeks, prior to the dispersal assay, population size (mean: $190 \mathrm{~mL}^{-1} \pm$ 9 SE; 95\% range [172; 208]) and infection prevalence (mean: $26.8 \% \pm 2.1 ; 95 \%$ range [3.1; 90.7]) had settled naturally in each experimental replicate.

Dispersal assay. We assayed the dispersal of infected and uninfected replicates in dispersal arenas, as described in Nørgaard et al. (2021). A dispersal arena consisted of three 50-mL Falcon tubes, linearly connected by $5-\mathrm{cm}$ long silicon tubing (inner diameter: $0.8 \mathrm{~cm}$ ). The 3-patch system was filled with $75 \mathrm{~mL}$ of medium to establish connections. Then the connections were blocked with clamps and $20 \mathrm{~mL}$ of a given replicate culture added into the middle tube. The lateral tubes received $20 \mathrm{~mL}$ of Paramecium-free medium. Connections were then opened, and the Paramecium allowed to disperse to the lateral tubes for $3 \mathrm{~h}$. After blocking the connections, we counted the individuals in samples from the middle tube (500- $\mu \mathrm{l})$ and from the combined lateral tubes $(3 \mathrm{~mL})$ to estimate the number of non-dispersing and dispersing individuals (dissecting microscope, 40x). From the same samples, we also made lacto-aceto-orcein fixations (Görtz \& Wiemann, 1989) and determined the infection status (infected / uninfected) of up to 30 dispersing and nondispersing individuals, respectively (light microscope, phase contrast, 1000x). From the cell counts and the infection status data, we estimated the population density and infection prevalence in the middle tube at the beginning of the assay. From the same data, we also estimated the proportion of infected and uninfected dispersers for each replicate, referred to as per-3h "dispersal rate" or dispersal, hereafter. 
bioRxiv preprint doi: https://doi.org/10.1101/2020.07.30.228742; this version posted March 7, 2021. The copyright holder for this preprint (which was not certified by peer review) is the author/funder, who has granted bioRxiv a license to display the preprint in perpetuity. It is made available under aCC-BY-NC 4.0 International license.

In addition, to investigate a potential link between dispersal and movement (Banerji et al., 2015; Pennekamp et al., 2019), we assayed swimming behaviour. For each strain, 1 infected and 1 uninfected individual were isolated from arbitrarily selected assay replicates, and allowed to replicate in a 2-mL plastic tubes for 8 days. For the resulting 40 monoclonal cultures (20 strains x 2 infection status) we placed $200-\mu \mathrm{L}$ samples (10-20 individuals) on a microscope slide and recorded individual movement trajectories under a Perfex Pro 10 stereomicroscope, using a Perfex SC38800 camera (15 frames per second; duration: 10 s; total magnification: 10x). For each sample, average swimming speed $(\mu \mathrm{m} / \mathrm{s})$ and swimming tortuosity (standard deviation of the turning angle distribution, describing the extent of swimming trajectory change) were determined using video analysis ("BEMOVI" package; Pennekamp et al., 2015).

\section{Statistical analysis}

Statistical analyses were conducted in R, v. 3.6.3 (R Core Team, 2020) using Bayesian models with the 'rstan' (version 2.19.3) and 'rethinking' (version 2.0.1) packages (McElreath 2020).

For state-dependent dispersal, we compared the dispersal of the infected individuals (in infected replicates) with the dispersal in the uninfected control replicates. We fitted four models, from the intercept to the full interaction model, using a binomial regression with logit link function (chain length: warmup $=20,000$ iterations, chain $=40,000$ iterations). In the full model, the explanatory factors were infection status (infected or uninfected control), Paramecium strain identity, and the strain $\mathrm{x}$ status interaction. Experimental block only explained a negligible fraction of the dispersal variation (preliminary analysis, not shown) and was omitted from all further analyses. We fitted the models choosing vaguely informative priors; the intercepts and slope parameters followed a normal distribution with mean -2 and standard deviation 3 for the first, and mean 0 and standard deviation 1.75 for the latter. To account for overdispersion we included an observationlevel random effect. The mean and standard deviation of the observation-level hyperprior followed a normal and half-normal distribution respectively, with mean 0 and standard deviation 1 . The four state-dependent models were compared and ranked using the Watanabe-Akaike information criterion, WAIC (Watanabe, 2010), a generalized version of the Akaike information criterion (Gelman et al., 2014). The posterior predictions of the models were then averaged based on WAIC weights, and the relative importance (RI) of the explanatory variables was calculated as the sum of the respective WAIC model weights in which that variable was included. Due to loss of replicates, low population density, and/or very low levels of infection, 159 replicates (from 20 strains) of the 180 initial replicates were available for this analysis.

For context-dependent dispersal, we analysed the dispersal of uninfected Paramecium in infected assay replicates. We fitted 6 models, from the intercept to the full interaction model, using the same binomial regression with logit link function, chain lengths and prior specifications as above. The explanatory factors of the full model (varying intercept and slope) were infection prevalence, strain identity and the strain $x$ 
infection prevalence interaction. The posterior predictions were averaged and ranked, and the RI calculated based on WAIC model weights as described above. For this analysis, 99 assay replicates (from 19 strains) of the initially 120 inoculated replicates were available.

We used similar analyses to test whether swimming speed and tortuosity varied as a function of strain identity and infection status. We standardized the response variable and fitted four models (from the intercept to the additive model, see Table S2 and S3, Supplementary Information) using a linear regression (chain length: warmup $=20,000$ iterations, chain $=40,000$ iterations) with an exponentially distributed prior ( rate $=1$ ) for standard deviation. As for the dispersal analysis, the parameter priors were vaguely informative; the intercept and slope parameters followed a normal distribution with mean 0 and standard deviation 2 . We averaged and ranked the posterior predictions, and we obtained RI based on WAIC model weights. We further tested for correlations between these two swimming traits and mean strain dispersal, for infected and uninfected Paramecium (chain length: warmup $=2,000$ iterations, chain $=10,000$ iterations). Due to missing data, only 17 of the 20 strains were used for these analyses.

\section{Results}

\section{State-dependent dispersal}

Our analysis revealed substantial variation in constitutive dispersal among the $20 \mathrm{P}$. caudatum strains (relative importance, $\mathrm{RI}$, of strain identity $=0.85$; Table 1$)$, ranging from $1 \%$ ( $95 \%$ compatibility Interval $[0.001$; $0.135])$ to $41 \%$ ([0.02;0.80]) of the individuals moving from the central to the lateral tubes (Fig. 1A). Our models provided limited evidence for state-dependent dispersal plasticity. Infection status $(\mathrm{RI}=0.57)$ was retained in the best model fit (lowest WAIC; Model 3 in Table 1), indicating a general trend of infection to increase host dispersal. Even though the signal of the strain $\mathrm{x}$ infection status interaction $(\mathrm{RI}=0.22)$ was only weak, patterns in Fig. 1B indicate that effects of infection varied with strain identity: several strains indeed dispersed more when infected (Fig. 1B right side of panel), but in at least half of the strains, infection had little effect or decreased host dispersal.

\section{Context-dependent dispersal}

As in the above analysis, we found substantial genotypic variation in overall constitutive levels of dispersal for uninfected Paramecium (RI of strain identity $=0.80$; Table 2). The best model (model 4 in Table 2 ) included an effect of infection prevalence $(\mathrm{RI}=0.67)$, and thus context-dependent dispersal. Namely, uninfected individuals tended to disperse less at higher parasite infection prevalence in the population (Fig. 2): such negative dispersal-prevalence relationships were predicted for all but one strain (negative median slope values; Fig. 2B). To some degree, however, the strength of this relationship varied between strains (RI of infection prevalence $x$ strain interaction $=0.21$ ). As shown in Fig. $2 \mathrm{~B}$, distributions of predicted slopes show 
bioRxiv preprint doi: https://doi.org/10.1101/2020 07.30.228742; this version posted March 7 , 2021. The copyright holder for this preprint (which was not certified by peer review) is the author/funder, who has granted bioRxiv a license to display the preprint in perpetuity. It is made available under aCC-BY-NC 4.0 International license.

considerable variation and for the majority of strains there is considerable overlap with 0 . Only a small number of strains (e.g., C139, C116, C083) show clearly negative slopes (Fig. 2B).

\section{Swimming behaviour}

The analysis of standardized swimming speed revealed strong effects of strain identity (RI = 0.9; Table S2) and infection status (RI = 1; Table S2). Namely, standardized swimming speed of uninfected Paramecium (median $=0.57,95 \% \mathrm{Cl}[-0.64 ; 2.34]$ ) was generally higher than that of infected ones (median $=-1.20,95 \% \mathrm{Cl}$ $[-1.63 ;-0.77])$, corresponding to a difference of almost $40 \%$ (median $=0.39,95 \% \mathrm{Cl}[0.10 ; 0.68]$; Fig. S1A-B). Swimming tortuosity was not affected by strain and weakly affected by infection status (RI strain = 0 ; RI status $=0.28$; Table S3). Neither swimming speed (uninfected: $r=0.08,95 \% \mathrm{Cl}[-0.39 ; 0.52]$; infected: $r=0.07,95 \%$ $\mathrm{Cl}[-0.41 ; 0.54]$ ) nor swimming tortuosity (uninfected: $r=0.15,95 \% \mathrm{Cl}[-0.29 ; 0.56]$; infected: $r=-0.10,95 \%$ $\mathrm{Cl}[-0.55 ; 0.39])$ were strongly correlated with dispersal.

\section{Discussion}

Dispersal affects epidemiology and host-parasite (co)evolution in metapopulations (Lion \& Gandon, 2015; Parratt et al., 2016), but how dispersal itself evolves due to antagonistic species interactions is less well known (Poethke et al., 2010; Drown et al., 2013; Deshpande et al., 2021). Here we focused on dispersal plasticity in response to parasitism, which may evolve as a means to reduce infection risk of the dispersing individuals and/or their relatives (Iritani \& Iwasa, 2014; Iritani, 2015; Deshpande et al., 2021). Our study takes a first step towards an understanding of population-level processes, by measuring dispersal of infected and uninfected hosts in experimental microcosms and by exploring the genetic variation in plasticity for a collection of host strains. Overall, signals of dispersal plasticity were weak. Both infection status and infection prevalence modified dispersal to some degree, with at least some strains showing indications of statedependent dispersal (i.e., when infected) and/or context-dependent dispersal (i.e., in response to infection prevalence).

\section{State-dependent plasticity: the dispersal of infected hosts}

In previous studies, infection by $H$. undulata reduced dispersal in $P$. caudatum for a small set of strains (Fellous et al., 2011; Nørgaard et al., 2021). Here we used strains from a worldwide collection (Table S1) and find the entire range of trends, from negative or no impact of infection to even positive effects on host dispersal (Fig. 1). Reduced host dispersal may be explained by general negative effects of infection, through the energetic demand of an immune response, the diversion of host resources by the parasite or direct physical damage (Mideo, 2009). Indeed, H. undulata consumes nuclear proteins and nucleotides (Garushyants et al., 2018) and also causes massive interior swelling of the infected micronucleus, which would explain the clear and pervasive reduction in swimming speed observed in the complementary 
bioRxiv preprint doi: https:/doi.org/10.1101/2020.07 30.228742; this version posted March 7, 2021. The copyright holder for this preprint (which was not certified by peer review) is the author/funder, who has granted bioRxiv a license to display the preprint in perpetuity. It is made available under aCC-BY-NC 4.0 International license.

experiment (Fig. S1A-B). However, dispersal reductions were far from being universal, suggesting that the amount of host damage differs between genotypes. Differential fitness effects (virulence) and variation in resistance are known for this system (Restif \& Kaltz, 2006), indicating the strong potential for genotypicspecificity in the responses to this parasite.

Moreover, it should be noted that the absence of a difference between infected and uninfected dispersal does not necessarily mean the absence of plasticity. Infected hosts may compensate parasite damage by reallocating resources to maintain vital functions, such as foraging and feeding activity, and this may lead to a net-zero effect of infection on dispersal. Interestingly, some of our strains even seemed to 'overcompensate' and dispersed more when infected. Such a positive state-dependent dispersal may be selectively favoured in a metapopulation because it can reduce kin competition and kin infection (Iritani \& Iwasa, 2014; Iritani, 2015; Deshpande et al., 2021). However, increased host dispersal may equally well reflect parasite manipulation, enhancing its dispersal to novel infection sites (Kamo \& Boots, 2006; Lion et al., 2006; Martini et al., 2015).

The main purpose here was to quantify the (variation in) population-level effects of infection on dispersal. More work is needed to better understand the links between parasite action, host movement and dispersal. This concern, for example the relationship between parasite load, virulence and dispersal. Furthermore, unlike in other protists (Pennekamp et al., 2019), swimming speed was not a good predictor of dispersal. Other aspects of swimming behaviour (Ricci, 1989) may be more relevant in our system. Namely, Paramecium show a characteristic vertical distribution (Fels et al., 2008) relating to food and oxygen availability (Wichterman, 2012). Parasites are known to affect the position of hosts in the water column (Cezilly et al., 2000; Fels et al., 2004), and this may directly influence the probability of infected individuals finding the dispersal corridors in our microcosms.

\section{Context-dependent plasticity: the dispersal of uninfected hosts}

Predator chemical signals induce dispersal in various organisms, including $P$. caudatum (Fronhofer et al. 2018). We tested for a similar parasite effect in our microcosm populations, by measuring the dispersal of uninfected hosts at different infection prevalences, with the assumption that higher prevalence equals a stronger signal of 'parasite presence'. Unlike in the predator-cues study, we found little evidence for a positive dispersal-inducing effect. Dispersal decreased at higher infection prevalence, at least for certain strains. Interestingly, Deshpande et al.'s model (2021) predicts the evolution of such negative prevalencedependent dispersal, as the result of complex spatio-temporal variations in eco-evolutionary processes. We do not know the evolutionary history of the strains, but our results suggest a possible genetic basis of contextdependent dispersal in this system and hence genetic variation that might be seen by natural selection. 
bioRxiv preprint doi: https:/doi.org/10.1101/2020.07.30.228742; this version posted March 7, 2021. The copyright holder for this preprint (which was not certified by peer review) is the author/funder, who has granted bioRxiv a license to display the preprint in perpetuity. It is made available under aCC-BY-NC 4.0 International license.

Our experimental approach of using naturally established infection prevalence may not have produced strong enough signal variation for all strains. This could be remedied via more artificial designs, by mixing of infected and uninfected individuals to establish well-defined gradients. Infected cultures or inocula may also be filtered to specifically test for chemical cues (see Fronhofer et al., 2018). Finally, we made the simplifying assumption of linear dispersal reaction norms. However, dispersal responses may well follow non-linear rules, e.g., if there are signal thresholds (Fronhofer et al., 2015b), as observed for other traits (Morel-Journel et al., 2020) and predicted by Deshpande et al. (2021). Tests for non-linear relationships would require a much finer resolution (i.e., more replication) on the signal axis.

\section{Conditions for plasticity selection: outlook}

The heritability of phenotypic plasticity of morphological or behavioural traits is generally lower than their constitutive heritability (Scheiner, 1993; Stirling et al., 2002). In line with this, we find much less among-strain differentiation for parasite-related dispersal plasticity than for constitutive dispersal, suggesting a weaker potential for responding to selection. However, the available genetic variation alone does not determine the relative importance of phenotypic plasticity in shaping evolutionary trajectories (Stamp \& Hadfield, 2020). Phenotypic plasticity is generally favoured in variable, but nonetheless predictable environments (Leung et al., 2020). In a parasite context, dispersal plasticity evolution may thus depend on the spatio-temporal predictability of parasite encounter rates across a metapopulation (Deshpande et al., 2021). Additional factors are parasite virulence, the cost of dispersal (or its advantage if parasite release is possible during dispersal), or correlations with other traits (Iritani \& Iwasa, 2014). For example, a recent experiment with the protist Tetrahymena revealed few genetic constraints on the concurrent evolution of plasticity across various traits (Morel-Journel et al., 2020). Indeed, state- and context-dependent dispersal might also evolve simultaneously in the presence of parasites, even though not necessarily in a correlated fashion (Deshpande et al., 2021). Our data indicate no genetic correlation between state- and context-dependent plasticity $(r=-$ $0.11,95 \% \mathrm{Cl}[-0.55 ; 0.36]$; based on strain averages), suggesting that independent responses to selection are possible, as shown in the model.

Our study represents one of the first accounts of the naturally existing genetic variation for state-dependent and context-dependent dispersal plasticity in relation to parasites. The signals of plasticity are weak and there are many open questions regarding the mechanistic and physiological basis of trait expression or information use. Nonetheless, in microbial systems such as ours, the observed variation opens promising avenues for future experiments. In microcosm landscapes, allowing the free interplay between dispersal and epidemiological processes, we can assess how dispersal plasticity affects parasite spread at the metapopulation level. Over longer time spans, we can also explore dispersal evolution and test evolutionary predictions on dispersal plasticity and its adaptive role in host-parasite interactions. 


\section{Data availability statement}

334 The experimental data will be made available upon potential acceptance (via Dryad/Figshare repository).

\section{References}

Baines, C.B., Diab, S. \& McCauley, S.J. 2020. Parasitism Risk and Infection Alter Host Dispersal. Am. Nat. 000000. The University of Chicago Press.

Banerji, A., Duncan, A.B., Griffin, J.S., Humphries, S., Petchey, O.L. \& Kaltz, O. 2015. Density- and traitmediated effects of a parasite and a predator in a tri-trophic food web. J. Anim. Ecol. 84: 723-733.

Behringer, D.C., Butler, M.J. \& Shields, J.D. 2006. Avoidance of disease by social lobsters. Nature 441: 421421. Nature Publishing Group.

Binning, S.A., Shaw, A.K. \& Roche, D.G. 2017. Parasites and Host Performance: Incorporating Infection into Our Understanding of Animal Movement. Integr. Comp. Biol. 57: 267-280. Oxford Academic.

Bonte, D. \& Dahirel, M. 2017. Dispersal: a central and independent trait in life history. Oikos 126: 472-479.

Bowler, D.E. \& Benton, T.G. 2005. Causes and consequences of animal dispersal strategies: relating individual behaviour to spatial dynamics. Biol. Rev. 80: 205-225.

Brown, G.P., Kelehear, C., Pizzatto, L. \& Shine, R. 2016. The impact of lungworm parasites on rates of dispersal of their anuran host, the invasive cane toad. Biol. Invasions 18: 103-114.

Cezilly, F., Gregoire, A. \& Bertin, A. 2000. Conflict between co-occurring manipulative parasites? An experimental study of the joint influence of two acanthocephalan parasites on the behaviour of Gammarus pulex. Parasitology 120: 625-630. Cambridge University Press.

Chevin, L.-M., Gallet, R., Gomulkiewicz, R., Holt, R.D. \& Fellous, S. 2013. Phenotypic plasticity in evolutionary rescue experiments. Philos. Trans. R. Soc. B Biol. Sci. 368.

Clobert, J., Galliard, J.-F.L., Cote, J., Meylan, S. \& Massot, M. 2009. Informed dispersal, heterogeneity in animal dispersal syndromes and the dynamics of spatially structured populations. Ecol. Lett. 12: 197209. 
Cote, J., Bestion, E., Jacob, S., Travis, J., Legrand, D. \& Baguette, M. 2017. Evolution of dispersal strategies and dispersal syndromes in fragmented landscapes. Ecography 40: 56-73.

Csata, E., Bernadou, A., Rakosy-Tican, E., Heinze, J. \& Marko, B. 2017. The effects of fungal infection and physiological condition on the locomotory behaviour of the ant Myrmica scabrinodis. J. Insect Physiol. 98: 167-172.

Curtis, V.A. 2014. Infection-avoidance behaviour in humans and other animals. Trends Immunol. 35: 457464.

Daversa, D.R., Fenton, A., Dell, A.I., Garner, T.W.J. \& Manica, A. 2017. Infections on the move: how transient phases of host movement influence disease spread. Proc. R. Soc. B Biol. Sci. 284: 20171807.

de la Pena, E., D’hondt, B. \& Bonte, D. 2011. Landscape structure, dispersal and the evolution of antagonistic plant-herbivore interactions. Ecography 34: 480-487.

Deshpande, J.N., Kaltz, O. \& Fronhofer, E.A. 2021. Host-parasite dynamics set the ecological theatre for the evolution of state- and context-dependent dispersal in hosts. Oikos 130: 121-132.

Dohra, H., Suzuki, H., Suzuki, T., Tanaka, K. \& Fujishima, M. 2013. Draft Genome Sequence of Holospora undulata Strain HU1, a Micronucleus-Specific Symbiont of the Ciliate Paramecium caudatum. Genome Announc. 1.

Drown, D.M., Dybdahl, M.F. \& Gomulkiewicz, R. 2013. Consumer-Resource Interactions and the Evolution of Migration. Evolution 67: 3290-3304.

Fellous, S., Quillery, E., Duncan, A.B. \& Kaltz, O. 2011. Parasitic infection reduces dispersal of ciliate host. Biol. Lett. 7: 327-329.

Fels, D., Lee, V.A. \& Ebert, D. 2004. The impact of microparasites on the vertical distribution of Daphnia magna. Arch. Für Hydrobiol. 161: 65-80.

Fels, D., Vignon, M. \& Kaltz, O. 2008. Ecological and genetic determinants of multiple infection and aggregation in a microbial host-parasite system. Parasitology 135: 1373-1383. Cambridge University Press.

Fokin, S.I. 2004. Bacterial endocytobionts of ciliophora and their interactions with the host cell. Int. Rev. Cytol. 236: 181-250. New York, NY: Academic Press, 1952-.

French, D. \& Travis, J. 2001. Density-dependent dispersal in host-parasitoid assemblages. Oikos 95: 125-135. 
Fronhofer, E.A., Klecka, J., Melián, C.J. \& Altermatt, F. 2015a. Condition-dependent movement and dispersal in experimental metacommunities. Ecol. Lett. 18: 954-963.

Fronhofer, E.A., Kropf, T. \& Altermatt, F. 2015b. Density-dependent movement and the consequences of the Allee effect in the model organism Tetrahymena. J. Anim. Ecol. 84: 712-722.

Fronhofer, E.A., Legrand, D., Altermatt, F., Ansart, A., Blanchet, S., Bonte, D., et al. 2018. Bottom-up and topdown control of dispersal across major organismal groups. Nat. Ecol. Evol. 2: 1859-1863. Nature Publishing Group.

Garland, T. \& Kelly, S.A. 2006. Phenotypic plasticity and experimental evolution. J. Exp. Biol. 209: 2344-2361.

Garushyants, S.K., Beliavskaia, A.Y., Malko, D.B., Logacheva, M.D., Rautian, M.S. \& Gelfand, M.S. 2018. Comparative Genomic Analysis of Holospora spp., Intranuclear Symbionts of Paramecia. Front. Microbiol. 9. Frontiers.

Gelman, A., Hwang, J. \& Vehtari, A. 2014. Understanding predictive information criteria for Bayesian models. Stat. Comput. 24: 997-1016.

Görtz, H.-D. \& Wiemann, M. 1989. Route of infection of the bacteria Holospora elegans and Holospora obtusa into the nuclei of Paramecium caudatum. Eur. J. Protistol. 24: 101-109.

Hanski, I. 1999. Metapopulation Ecology. Oxford University Press, Oxford, New York.

Iritani, R. 2015. How parasite-mediated costs drive the evolution of disease state-dependent dispersal. Ecol. Complex. 21: 1-13.

Iritani, R. \& Iwasa, Y. 2014. Parasite infection drives the evolution of state-dependent dispersal of the host. Theor. Popul. Biol. 92: 1-13.

Kamo, M. \& Boots, M. 2006. The evolution of parasite dispersal, transmission, and virulence in spatial host populations. Evol. Ecol. Res. 8: 1333-1347.

Koskella, B., Taylor, T.B., Bates, J. \& Buckling, A. 2011. Using experimental evolution to explore natural patterns between bacterial motility and resistance to bacteriophages. ISME J. 5: 1809-1817.

Laitinen, R.A.E. \& Nikoloski, Z. 2019. Genetic basis of plasticity in plants. J. Exp. Bot. 70: 739-745.

Leggett, H.C., Benmayor, R., Hodgson, D.J. \& Buckling, A. 2013. Experimental Evolution of Adaptive Phenotypic Plasticity in a Parasite. Curr. Biol. 23: 139-142. 
Leung, C., Rescan, M., Grulois, D. \& Chevin, L.-M. n.d. Reduced phenotypic plasticity evolves in less predictable environments. Ecol. Lett. 23: 1664-1672.

Lion, S. \& Gandon, S. 2015. Evolution of spatially structured host-parasite interactions. J. Evol. Biol. 28: 1028.

Lion, S., van Baalen, M. \& Wilson, W.G. 2006. The evolution of parasite manipulation of host dispersal. Proc. R. Soc. B Biol. Sci. 273: 1063-1071. Royal Society.

Martini, X., Hoffmann, M., Coy, M.R., Stelinski, L.L. \& Pelz-Stelinski, K.S. 2015. Infection of an Insect Vector with a Bacterial Plant Pathogen Increases Its Propensity for Dispersal. PLoS One 10.

McElreath, R. 2020. Statistical rethinking: a Bayesian course with examples in R and Stan. 2nd ed. Chapman and Hall/CRC, Boca Raton, FL.

Mideo, N. 2009. Parasite adaptations to within-host competition. Trends Parasitol. 25: 261-268.

Morel-Journel, T., Thuillier, V., Pennekamp, F., Laurent, E., Legrand, D., Chaine, A.S., et al. 2020. A multidimensional approach to the expression of phenotypic plasticity. Funct. Ecol. 34: 2338-2349.

Narayanan, N., Binning, S.A. \& Shaw, A.K. 2020. Infection state can affect host migratory decisions. Oikos 129: 1493-1503.

Nelson, F.B.L., Brown, G.P., Dubey, S. \& Shine, R. 2015. The Effects of a Nematode Lungworm (Rhabdias hylae) on its Natural and Invasive Anuran Hosts. J. Parasitol. 101: 290-296. American Society of Parasitologists.

Nørgaard, L.S., Phillips, B.L. \& Hall, M.D. 2019. Infection in patchy populations: Contrasting pathogen invasion success and dispersal at varying times since host colonization. Evol. Lett. 3: 555-566.

Nørgaard, L.S., Zilio, G., Saade, C., Gougat-Barbera, C., Hall, M.D., Fronhofer, E.A., et al. 2021. An evolutionary trade-off between parasite virulence and dispersal at experimental invasion fronts. Ecol. Lett. ele.13692.

Parmesan, C. \& Yohe, G. 2003. A globally coherent fingerprint of climate change impacts across natural systems. Nature 421: 37-42. Nature Publishing Group.

Parratt, S.R., Numminen, E. \& Laine, A.-L. 2016. Infectious Disease Dynamics in Heterogeneous Landscapes. Annu. Rev. Ecol. Evol. Syst. 47: 283-306. 
Pennekamp, F., Clobert, J. \& Schtickzelle, N. 2019. The interplay between movement, morphology and dispersal in Tetrahymena ciliates. PeerJ 7: e8197. PeerJ Inc.

Pennekamp, F., Schtickzelle, N. \& Petchey, O.L. 2015. BEMOVI, software for extracting behavior and morphology from videos, illustrated with analyses of microbes. Ecol. Evol. 5: 2584-2595.

Pigliucci, M. 2005. Evolution of phenotypic plasticity: where are we going now? Trends Ecol. Evol. 20: 481486.

Poethke, H.J., Weisser, W.W. \& Hovestadt, T. 2010. Predator-Induced Dispersal and the Evolution of Conditional Dispersal in Correlated Environments. Am. Nat. 175: 577-586. The University of Chicago Press.

R Core Team (2020). R: A language and environment for statistical computing. R Foundation for Statistical Computing, Vienna, Austria.

Restif, O. \& Kaltz, O. 2006. Condition-dependent virulence in a horizontally and vertically transmitted bacterial parasite. Oikos 114: 148-158.

Ricci, N. 1989. Locomotion as a criterion to read the adaptive biology of Protozoa and their evolution toward Metazoa. Boll. Zool. 56: 245-263. Taylor \& Francis.

Ronce, O. 2007. How Does It Feel to Be Like a Rolling Stone? Ten Questions About Dispersal Evolution. Annu. Rev. Ecol. Evol. Syst. 38: 231-253.

Saastamoinen, M., Bocedi, G., Cote, J., Legrand, D., Guillaume, F., Wheat, C.W., et al. 2018. Genetics of dispersal. Biol. Rev. 93: 574-599.

Scheiner, S.M. 1993. Genetics and Evolution of Phenotypic Plasticity. Annu. Rev. Ecol. Syst. 24: 35-68.

Shaw, A.K. \& Binning, S.A. 2016. Migratory Recovery from Infection as a Selective Pressure for the Evolution of Migration. Am. Nat. 187: 491-501. The University of Chicago Press.

Stamp, M.A. \& Hadfield, J.D. 2020. The relative importance of plasticity versus genetic differentiation in explaining between population differences; a meta-analysis. Ecol. Lett. 23: 1432-1441.

Stevens, V.M., Whitmee, S., Galliard, J.-F.L., Clobert, J., Böhning-Gaese, K., Bonte, D., et al. 2014. A comparative analysis of dispersal syndromes in terrestrial and semi-terrestrial animals. Ecol. Lett. 17: 1039-1052. 
Stirling, D.G., Réale, D. \& Roff, D.A. 2002. Selection, structure and the heritability of behaviour. J. Evol. Biol. 15: 277-289.

Suhonen, J., Honkavaara, J. \& Rantala, M.J. 2010. Activation of the immune system promotes insect dispersal in the wild. Oecologia 162: 541-547.

Watanabe, S. 2010. Asymptotic Equivalence of Bayes Cross Validation and Widely Applicable Information Criterion in Singular Learning Theory. J. Mach. Learn. Res. 11: 3571-3594.

Weisser, W.W., Braendle, C. \& Minoretti, N. 1999. Predator-induced morphological shift in the pea aphid. Proc. R. Soc. Lond. B Biol. Sci. 266: 1175-1181. Royal Society.

Wichterman, R. 2012. The Biology of Paramecium. Springer Science \& Business Media.

Zilio, G., Nørgaard, L.S., Gougat-Barbera, C., Hall, M.D., Fronhofer, E.A. \& Kaltz, O. 2020. Travelling with a parasite: the evolution of resistance and dispersal syndrome during experimental range expansion. bioRxiv 2020.01.29.924498. Cold Spring Harbor Laboratory. 
bioRxiv preprint doi: https://doi.org/10.1101/2020.07.30.228742; this version posted March 7,2021 . The copyright holder for this preprint (which was not certified by peer review) is the author/funder, who has granted bioRxiv a license to display the preprint in perpetuity. It is made available under aCC-BY-NC 4.0 International license.

495

496

497

498

499

500

501

502

503

504

505

506

507

Table 1. Different statistical models and parameters included for the analysis and model averaging of the statedependent dispersal. The rows represent the different models (the best model is highlighted in bold) and the columns the factors included in each model with the corresponding WAIC, standard error of the WAIC and WAIC weights. The RI row shows the relative importance of the explanatory variables.

\begin{tabular}{c|c|c|c||c|c|c} 
& Strain & Status & Strain * Status & WAIC & SE & WAIC weight \\
\hline Model 1 & & & & 1165 & 7.36 & 0.15 \\
\hline Model 2 & $\mathrm{X}$ & & & 1163.8 & 27.76 & 0.27 \\
\hline Model 3 & $\mathbf{X}$ & $\mathbf{X}$ & & $\mathbf{1 1 6 3 . 3}$ & $\mathbf{2 7 . 6 7}$ & $\mathbf{0 . 3 5}$ \\
\hline Model 4 & $\mathrm{X}$ & $\mathrm{X}$ & $\mathrm{X}$ & 1164.3 & 7.68 & 0.22 \\
\hline \hline $\mathrm{RI}$ & 0.85 & 0.57 & 0.22 & &
\end{tabular}

Table 2. Statistical models and parameters for the analysis and model averaging of the context-dependent dispersal. Each row represents a different model, the best model is highlighted in bold and the last row indicates the relative importance (RI) of the explanatory variables. The columns are the variables included in the six models with the corresponding WAIC, standard error of the WAIC and WAIC weights.

\begin{tabular}{c|c|c|c|c|c|c} 
& Strain & Prevalence & Strain * Prevalence & WAIC & SE & WAIC weight \\
\hline Model 1 & & & & 746.4 & 17.97 & 0.10 \\
\hline Model 2 & $\mathrm{X}$ & & & 744.6 & 18.62 & 0.23 \\
\hline Model 3 & & $\mathrm{X}$ & & 746.4 & 17.93 & 0.10 \\
\hline Model 4 & $\mathrm{X}$ & $\mathrm{X}$ & & $\mathbf{7 4 4 . 2}$ & $\mathbf{1 8 . 7 7}$ & $\mathbf{0 . 2 8}$ \\
\hline Model 5 & $\mathrm{X}$ & $\mathrm{X}$ & & 746.7 & 18.16 & 0.08 \\
\hline Model 6 & $\mathrm{X}$ & $\mathrm{X}$ & $\mathrm{X}$ & 744.8 & 18.61 & 0.21 \\
\hline \hline $\mathrm{RI}$ & 0.80 & 0.67 & 0.21 & & &
\end{tabular}


bioRxiv preprint doi: https://doi.org/10.1101/2020.07.30.228742; this version posted March 7,2021 . The copyright holder for this preprint (which was not certified by peer review) is the author/funder, who has granted bioRxiv a license to display the preprint in perpetuity. It is made available under aCC-BY-NC 4.0 International license.

\section{Figures}

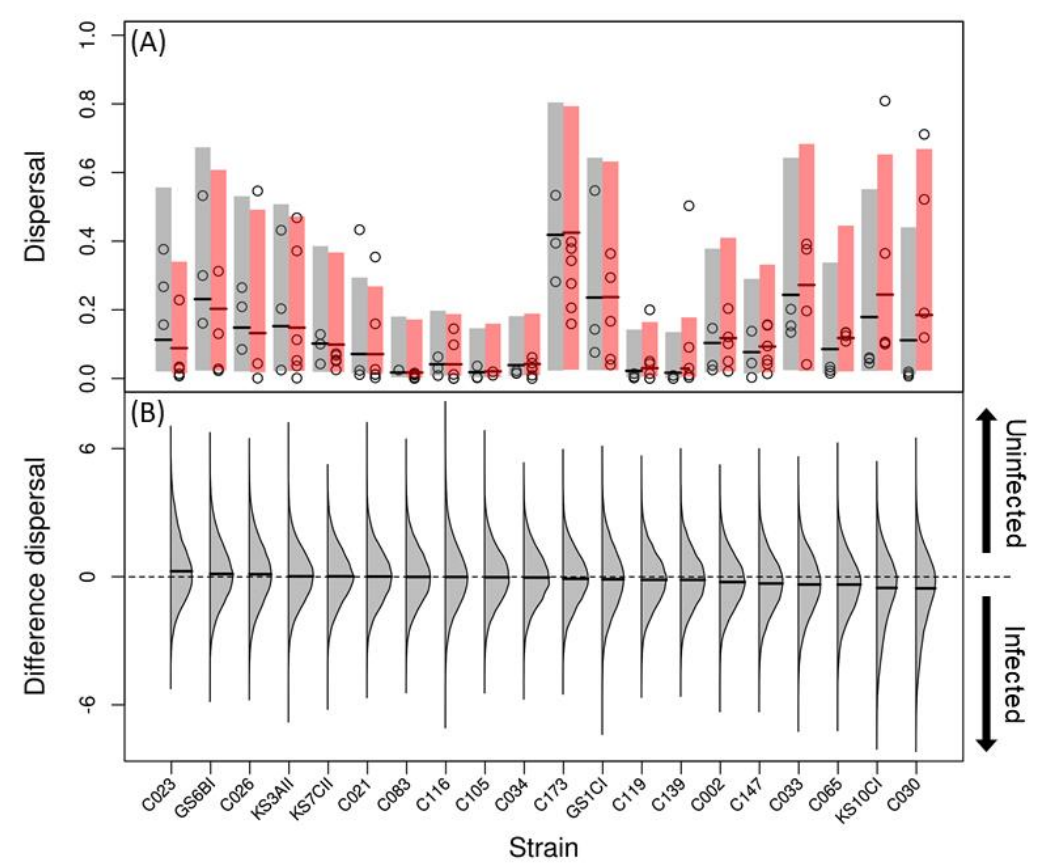

513

514 Figure 1. State-dependent dispersal of 20 Paramecium caudatum strains, as a function of infection status (uninfected /

515 infected with Holospora undulata). (A) Shaded bars and thick lines represent the 95\% compatibility interval and the median of the averaged model predictions of the posterior distributions. Strains are ordered according to the difference between uninfected (grey) and infected (red) dispersal. Each circle represents an experimental replicate. (B) Difference between uninfected and infected averaged model posterior predictions for each strain (expressed in logits), the thick black line represents the median of the difference distribution. Distributions shifted below zero (dashed grey line) indicates higher dispersal in the infected (pointing-down arrow) compared to the uninfected (pointing-up arrow) treatment. 
(A)

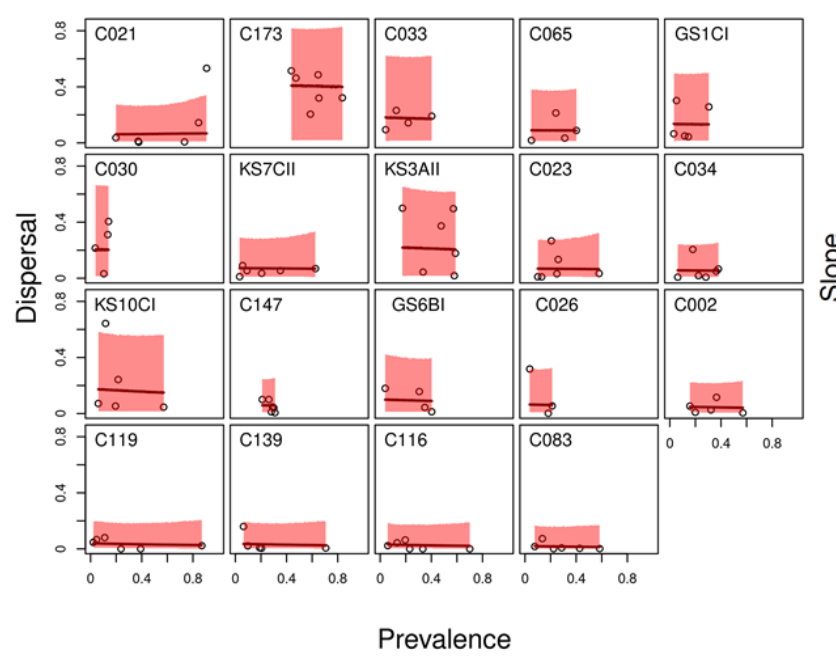

(B)

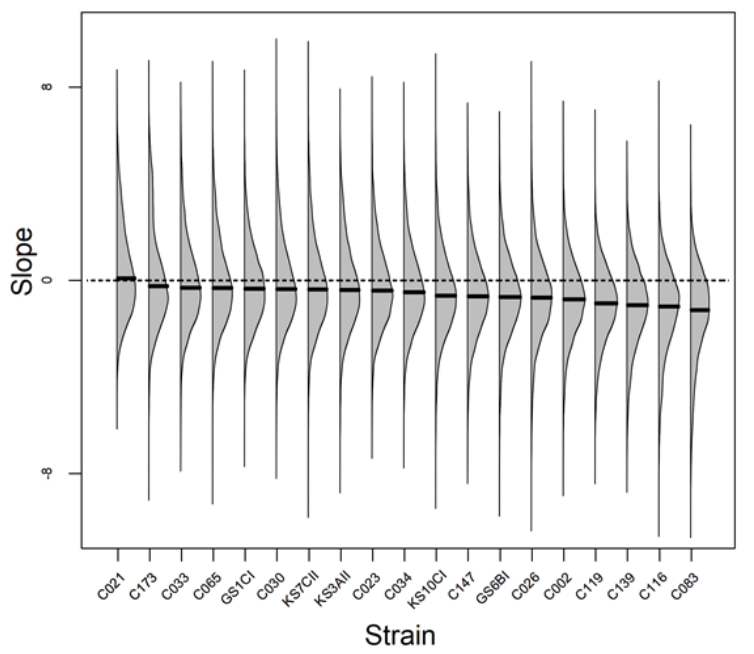

Figure 2. Context-dependent dispersal of 19 uninfected Paramecium caudatum strains, as a function of parasite (Holospora undulata) infection prevalence in the microcosm population. (A) Each panel represents a strain, and each circle an experimental replicate; the red shaded area and thick red lines are the $95 \%$ compatibility interval and median of the averaged model of the posterior distributions. (B) Averaging of the posterior distributions of the slope parameter calculated in logit (model 3-6, Table 2) with the thick black lines showing the median. Positive or negative slopes distributions (above or below zero, dashed grey line), indicate a higher or lower dispersal in response to increasing frequency of infected hosts. 


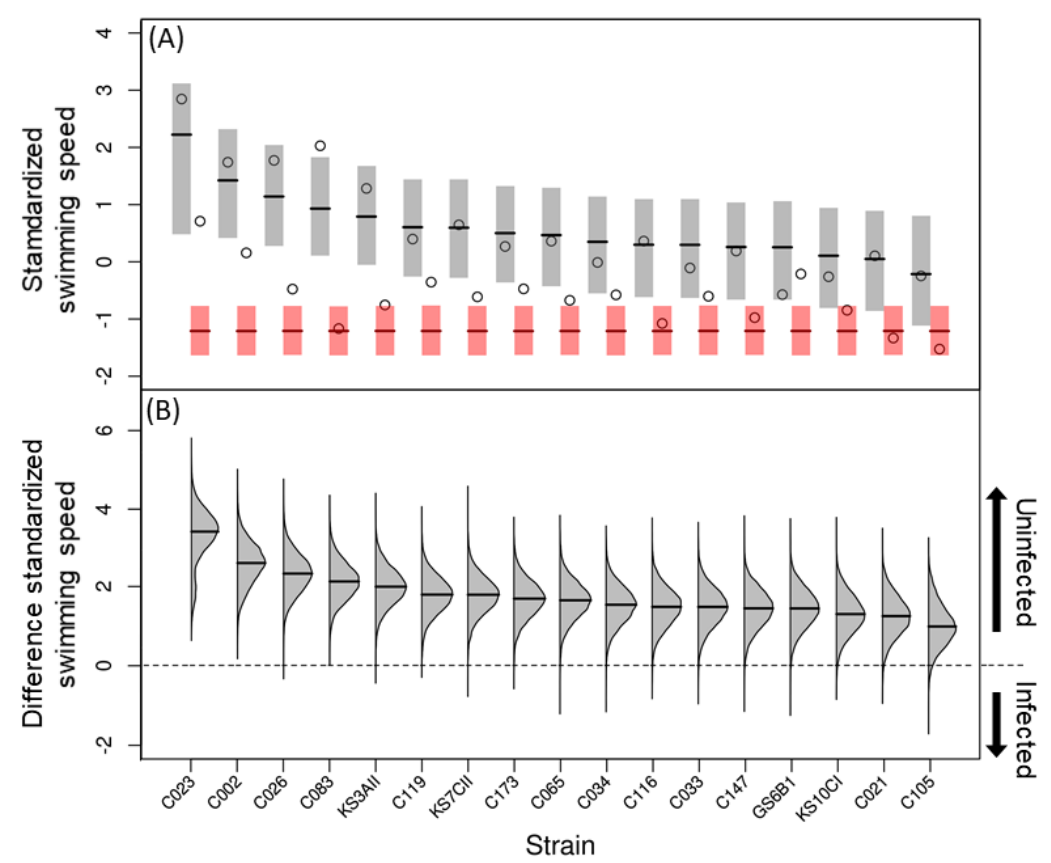

Figure S1. Standardized swimming speed of 17 Paramecium caudatum, as a function of infection status (uninfected / infected with Holospora undulata). (A) Strains are ordered according to the difference between uninfected (grey) and infected (red) dispersal. Each circle represents an experimental replicate. Shaded bars and thick lines are the 95\% compatibility interval and median of the averaged model predictions of the posterior distributions, and each circle represents the measured data of swimming speed per strain. (B) The difference in swimming speed between uninfected and infected averaged model posterior predictions for each strain. The thick black lines are the median of the difference distribution. Distributions shifted above zero (dashed grey line) indicates higher swimming speed in the uninfected treatment (pointing-up arrow) compared to the infected treatment (pointing-down arrow). 
bioRxiv preprint doi: https://doi org/10.1101/2020.07.30.228742; this version posted March 7,2021 . The copyright holder for this preprint (which was not certified by peer review) is the author/funder, who has granted bioRxiv a license to display the preprint in perpetuity. It is made available under aCC-BY-NC 4.0 International license.

Table S1. Host strain identity, location of origin and GPS coordinates, $\left({ }^{*}\right)$ indicates approximate location.

\begin{tabular}{|c|c|c|c|}
\hline Strain & Location code & Origin & $\begin{array}{c}\text { GPS } \\
\text { coordinates }\end{array}$ \\
\hline COO2 & Hainberger See & Germany & $51.035688,12.285028$ \\
\hline C021 & Erzgebirge E1 & Germany & $50.647032,13.256963$ \\
\hline $\mathrm{CO23}$ & Plön K 2 & Germany & $54.15021,10.440307$ \\
\hline C026 & Fokin 1 UBR 42 & USA, Louisiana & $53.131996,13.107747$ \\
\hline C030 & Österreich_Lahnalp & Austria & $47.695948,12.218064\left(^{*}\right)$ \\
\hline $\mathrm{CO33}$ & Peking 1_C3 & China & $39.128165,117.185083\left(^{*}\right)$ \\
\hline C034 & Plön K 2 & Germany & $54.15021,10.440307$ \\
\hline C065 & SWE 17.1 & Sweden & $60.105747,15.966911$ \\
\hline C083 & USBL-5I1 & USA, Indiana & $39.069861,-86.414361$ \\
\hline C105 & Sp $10 \mathrm{C}$ & Spain & $39.548852,-1.502887$ \\
\hline C116 & Frankreich 10-2.1 & France & $43.430297,6.126616$ \\
\hline C119 & Peru & Peru & $-12.046184,-77.040842\left(^{*}\right)$ \\
\hline C139 & My43c3d & Japan & $38.480973,141.372414\left(^{*}\right)$ \\
\hline C147 & KNZ5414 & Japan & $36.519469,136.709415$ \\
\hline C173 & Greece 10.1 & Greece & $40.805947,21.983306$ \\
\hline GS1Cl & Globsowsee & Germany & $53.128590,13.118740$ \\
\hline GS6BI & Globsowsee & Germany & $53.128590,13.118740$ \\
\hline KS10Cl & Kochsee & Germany & 53.131996, 13.107747 \\
\hline KS3AII & Kochsee & Germany & $53.131996,13.107747$ \\
\hline KS7CII & Kochsee & Germany & $53.131996,13.107747$ \\
\hline
\end{tabular}


bioRxiv preprint doi: https://doi org/10.1101/2020.07.30.228742 this version posted March 7,2021 . The copyright holder for this preprint (which was not certified by peer review) is the author/funder, who has granted bioRxiv a license to display the preprint in perpetuity. It is made available under aCC-BY-NC 4.0 International license.

Table S2. Statistical models and parameters for the analysis and model averaging of the swimming speed. Each row shows a different model, from the intercept to the additive model. The best model is highlighted in bold and the last row indicates the relative importance $(\mathrm{RI})$ of the strain and status effect. The columns are the explanatory variables included in the four models with the corresponding WAIC, standard error of the WAIC and WAIC weights.

\begin{tabular}{c|c|c||c|c|c} 
& Strain & Status & WAIC & SE & WAIC weight \\
\hline Model 1 & & & 100.0 & 10.45 & 0.0 \\
\hline Model 2 & $\mathbf{X}$ & & 114.1 & 5.84 & 0.0 \\
\hline Model 3 & & $\mathbf{X}$ & 83.7 & 10.29 & 0.1 \\
\hline Model 4 & $\mathbf{X}$ & $\mathbf{X}$ & $\mathbf{7 9 . 4}$ & $\mathbf{7 . 5 6}$ & $\mathbf{0 . 9}$ \\
\hline \hline RI & 0.9 & 1.0 & \multicolumn{3}{|l}{}
\end{tabular}

Table S3. Models and parameters for the analysis and model averaging of the swimming tortuosity. Each row corresponds to a different model used for the analysis, with the best model is highlighted in bold. The last row shows the relative importance $(\mathrm{RI})$ of the explanatory variables. The columns are the variables of the models with the corresponding WAIC, standard error of the WAIC and WAIC weights.

\begin{tabular}{c|c|c||c|c|c} 
& Strain & Status & WAIC & SE & WAIC weight \\
\hline Model 1 & & & $\mathbf{9 9 . 1}$ & $\mathbf{6 . 5 2}$ & $\mathbf{0 . 7 2}$ \\
\hline Model 2 & $\mathrm{X}$ & & 119.4 & 5.89 & 0.00 \\
\hline Model 3 & & $\mathrm{X}$ & 101.0 & 6.39 & 0.28 \\
\hline Model 4 & $\mathrm{X}$ & $\mathrm{X}$ & 121.4 & 5.86 & 0.00 \\
\hline \hline RI & 0.00 & 0.28 & \multicolumn{3}{|l}{}
\end{tabular}

